\title{
Retrospective Assessment of Animals Experimentation Projects in Romania - A Critical Analysis of Non-Technical Summaries
}

\author{
Bogdan SEVASTRE ${ }^{1 *}$, Alexandra I. BLIDARU ${ }^{1}$, Orsolya SÁRPATAKI ${ }^{1}$, Ioan MARCUS ${ }^{1}$, and, Cristin COMAN $^{2}$ \\ ${ }^{1}$ University of Agricultural Science and Veterinary Medicine, Faculty of Veterinary Medicine, Manastur \\ Street no. 3-5, 400372, Cluj-Napoca, Romania, \\ ${ }^{2}$ National Institute Medico Military for Research and Development Cantacuzino, Splaiul Independentei \\ 103, district 5, 050096, Bucharest, Romania \\ *corresponding author: bogdan.sevastre@usamvcluj.ro
}

Bulletin UASVM Veterinary Medicine 75(2)/2018

Print ISSN 1843-5270; Electronic ISSN 1843-5378

doi:10.15835/buasvmcn-vm:2018.0014

\begin{abstract}
:
The aim of the present inquiry was to design an overview about the non-technical summaries available on the web page of the National Sanitary Veterinary and Food Safety Agency (Romania). We analyzed the compliance to the requirement of replacement, reduction and refinement (the $3 R^{\prime}$ s). 56 projects were found, the most of them (48), were assigned as "basic research", 2 as "translational and applied research", 2 as "regulatory use and routine analysis", while 4 projects targeted "higher education or training". The most common animals species used were rats, and mice, followed by rabbits, pigs, hamsters, guinea pigs and frogs (Rana sp.). According to cumulative severity of the project, 20 projects were classified as "severe", six as "moderate", three "mild", and three as "non-recovery". 24 projects had nor a severity assessment, neither a proper description of the level of severity. In our opinion, the number of projects classified as "severe" is too high; at least for some of them, the level of severity could be reduced using appropriate pain control techniques and / or human end-points. Overall, our recommendation is further improving the knowledge and skills of the personal involved in authorization and execution of the projects and of the authority inspectors that authorized the projects.
\end{abstract}

Keywords: 3R, laboratory animals, severity

\section{Introduction}

Nowadays, when animal studies are a controversial issue, there is a constant public pressure to limit and control any experiment conducted on animal models. In other to provide better control on animal studies and to increase the transparency, the Directive 2010/63/EU replaced the former Directive 86/609/EEC. In Romania, the Directive 2010/63/EU were transposed in the national legislation by Law no. 43 of 11 April 2014 of the Romanian Parliament on the protection of animals used for scientific purposes. The Order no. 97/2015 of the President of National Sanitary Veterinary and Food Safety Agency (NSVFSA) implemented projects authorization procedure, and since September $25^{\text {th }} 2015$ authorization of projects conducted on laboratory animals became a legal requirement. In Romania, project authorization consists in a two-step procedure, firstly, the applicant require the approval of the institutional Ethics Committee, and secondly, the authorization of regional Sanitary Veterinary authority (Coman et al., 2017) (Figure 1).

Similarly, to other EU countries, the applicants have to provide together to other documents also a non-technical summary (NTS) of the project, NTS dedicated to the general public. NTS is available on the web page of National Sanitary Veterinary and Food Safety Agency. A properly made NTS represent an essential tool for transparency of 
Table 1. Research projects available on the webpage of NSVFSA and their framing considering the severity vs purpose of project.

\begin{tabular}{|c|c|c|c|c|c|}
\hline \multirow[b]{2}{*}{ Severity } & \multirow[b]{2}{*}{ Total } & \multicolumn{4}{|c|}{ Purpose of Project: } \\
\hline & & Basic research & $\begin{array}{c}\text { Translational } \\
\text { and applied } \\
\text { research }\end{array}$ & $\begin{array}{c}\text { Regulatory use } \\
\text { and routine } \\
\text { analysis }\end{array}$ & $\begin{array}{c}\text { Higher } \\
\text { education } \\
\text { or training } \\
\end{array}$ \\
\hline mild & 3 & 3 & - & - & - \\
\hline moderate & 6 & 5 & - & - & 1 \\
\hline severe & 20 & 20 & - & - & - \\
\hline non-recovery & 3 & 3 & - & - & - \\
\hline no assessment & 24 & 17 & 2 & 2 & 3 \\
\hline Total & 56 & 48 & 2 & 2 & 4 \\
\hline
\end{tabular}

the scientific research activities, thus the general public should have access to easy understandable, but relevant data regarding the studies performed on the animals. However, the NTS should not disclose potential confidential information about scientists / institutions involved in study or serve as source of inspiration for concurrent scientists, which could thus "steal ideas".

The expertise of the personal involved in this process of drawing up project authorization dossiers varies widely among various research institutions, and even among research groups within the same institution. Before the abovementioned legislation, the authorization of the Laboratory Animals Establishments was also compulsory, but it was no need for project authorization. However, in many universities and research institutes the ethics committees were already established as an result of the demand of bioethical approval required by journals, but the formularies, the data requested and the approval conditions varied widely. Additionally, project authorization is a new challenge also for the veterinary state authorities, instruction of personal and elaboration of guidelines required a significant effort for the implementing team. Therefore, one can say that approval as well as reporting of projects is a new request in Romanian research institutions, thus, is not surprisingly that the process requires retrospective assessment and further improvement.

The aim of the present study was create an overview on the projects in Romania, as reflected by the NTSs available for public on the web page of the NSVFSA.

\section{Materials and methods}

The present study was achieved using public data available on June 2018 on web site of NSVFSA. We critically analyzed all the available non-technical summaries, including the purpose of the project, species and number of animals used the severity of the procedures, and the compliance with the requirement of replacement, reduction and refinement. NTS for authorization dossier and webpage is written in Romanian.

\section{Results and discussions}

On the web page of NSVFSA we found the NTSs of 56 animal research projects, the most of them (48), were assigned mainly as "basic research", 2 as "translational and applied research", 2 as "regulatory use and routine analysis", while 4 were dedicated to "higher education or training" (Table 1). This framing is only an approximately one, because a large number of projects were assigned to more than one purpose, despite the fact that the guidelines available on the website clearly specify that one project cannot have more than one purpose.

Firstly, we have noticed that a significant number of NTSs were filled in an inappropriate format; the applicants changed the standard format required. Some applicants did not understand the requirement of using a standardized formulary in order to respect the anonymous charter of the NTS and to provide a standardize set of data, which can be easily be followed by the public eye. Moreover in three NTSs the anonymous character was compromised by nomination of the animal establishment (the city 
and institution) (two NTSs), while in one they even mention the name of the person involved in the procedures. Other formal mistakes were the uses of incorrect terminology, like "biobase" instead of "establishment", "experiment" instead of "procedure" etc., which suggest that some applicants did not read the directive, legislation that, all begin with the definition of terms. Moreover, one application makes reference to the abrogated Directive 86/609/EEC. In the same way, the inspectors who authorized the mentioned projects did not report the mistakes in these NTSs and sent them for publication on veterinary authority webpage.

By far, the most common animals used were rats (Rattus norvegicus, B), and mice (Mus musculus, L), followed at large distance by rabbits (Orictolagus cuniculus, L), pigs (Sus scrofa, L), while hamsters (Mesocricetus auratus, W), Guinea pigs (Cavia porcellus, L) and frogs (Rana spp.) were used only in two and respectively one project. In the majority of the cases the number of animals proposed to be used in one project was low, ranging between 20-50 animals, relatively few projects used more than 50 animals. However, one project did not mention the number of animals used.

According to cumulative severity of the project, a number of 20 projects were classified as severe, six as moderate, three mild, and three as non-recovery. The remaining projects (34) had no severity assessment or the applicants describe separately the severity to each procedure or group of animal (Table 1). This is in contradiction with the guidelines, which assume only one severity level per project, representing the maximum severity the animals experience throughout the entire project. Among the three projects reported as non-recovery only 2 of them met the criteria of non-recovery. One of them was a project in which animals recover from anesthesia, but the applicant considers non-recovery because they were euthanized in the end of the project.

In the next step, we analyzed the compliance to the requirement of the $3 \mathrm{R}^{\prime} \mathrm{s}$, respectively replacement, reduction and refinement. We are fully aware that this assessment has a significant subjectivity; therefore, it should be perceive more as a point of view than as a categorical outcome. Moreover, we rely only on the data presented in the NTSs, thus is very likely that additional data might change the appreciation. However, we consider important the way in which the NTSs convince the public of the utility of the animal studies, which represent the primary objective of the NTS.

In the context of this study, we consider "basic research" all studies that did not aim to provide a new product or technology; even if the applicants indicated also other purposes like "translational and applied research" or "higher education and training". Overall, when we analyzed the project classified as "basic research" we found the most of them convincing and well documented. The scientific background of projects was found documented fairly well, and the large majority explains in a convincing manner the potential benefits, including elucidating mechanisms of relevant human disease, finding potential new molecules and biomaterial with potential for various therapies, novel surgical techniques, etc. However, when pointed the benefits of the study several applicants mentioned the publication of the articles, abstracts in conferences, writing dissertation or $\mathrm{PhD}$ thesis. From the point of view of the public, publishing an article is not a purpose by its own; it is just a way to disseminate the information. The benefit is the impact of information on scientific knowledge, and furthermore how this information can have a potential impact on human / animal health and welfare, environment protection, development of innovative technologies etc.

In terms of replacement, the most of the projects included in "basic research" explained in a convincing manner why the study could not be performed using alternative methods. However, one study investigating the cutaneous tolerance of a dermatological product used rabbits while widely accepted in vitro techniques suitable for skin irritation test are available. In such situation, the applicants should provide comprehensive explanations why this particular study cannot be done using in vitro models. As previously mentioned, the most of the projects used relatively small number of animals, the applicants mentioned bibliographical studies and statistical models used to reduce to the minimum the number of animals used. However, refinement requires significant improvements. Many authors have difficulties in classification of the severity of a project, 24 projects had no severity assessment or the applicants described improperly the le- 
vel of severity. Additionally a large number of projects were classified as severe, while in our opinion the level of severity could be reduced using appropriate pain control techniques and / or human end points, at least for part of the projects. Severe projects / procedures should be accepted only exceptionally, if the benefits are significant and refinement techniques are not available. As in the rest of the EU countries, the severity assessment is a problem, and it has been established that severity degree will be described and given for each procedure (Smith et al., 2018).

Importantly, all applicants describe anesthesia methods when the animals undergo surgery, or other painful procedures. However, only five of the NTSs describe the use of postsurgical pain management, and two described well-established criteria for human end points. Other appropriate refinement techniques commonly described were standardized environment conditions, qualified personal involved in restraining and procedures. In all cases, euthanasia was done using methods indicated by Directive 2010/63/EU, no derogation was mentioned. In all projects animal were euthanized in the end, the applicants mentioning no reuse or relocation of animals.

In the category "translational and applied research" we include only two projects, despite the fact that many of the projects assigned as "basic research" were also assigned as "translational and applied research". They were fully justified studies classified as mild.

Only two projects were classified as "regulatory use and routine analysis", which is surprising considering the fact that there are significant numbers of establishments associated to regional state veterinary authorities entirely dedicated to this purpose.

Only four projects were entirely dedicated to "higher education and training". Two of them were projects dedicated to training in surgery, involving non-recovery procedures on rats and pigs. Both studies were authorized for five years long, they use a relatively small number of animals, one study uses 130 rats and 10 rabbits annually, the other uses 10 pigs during all project. In our point of view, this is a fully acceptable purpose for an animal study. Only two projects were dedicated to undergraduate medical (involving 2500 rats) and biological students (20 rats and 100 frogs) respectively. Unfortunately, the NTSs did not describe exactly what procedures were performed, thus is impossible to appreciate if they are necessary or if alternative methods are available. However, one NTS mentioned that animals might suffer intoxications, hypoglycemic coma, convulsions etc. that suggests some demonstrative experiments easily replaceable with video recordings. In the absence of enough data, we cannot state a final point of view, but based on the available data we can say that these two NTSs provide not enough arguments to convince that educational animal procedure are strictly necessary and no replacement methods are available.

Noticeably, the webpage of NSVFSA provides all required information for properly writing the non-technical summaries; including the relevant legislation, Animal Care Guides, and a guide specifically design to support the applicants for project authorization. For the correct implementation of the new legislation regarding the authorization of the projects, the national authority together with the national scientific association in the field organized workshops in the main university centers of Romania. Researchers, staff experimenting with animals and inspectors from all the regional centers of the veterinary authority, inspectors who were to authorize the projects, attended these workshops. In all authorized establishments as users of animals for scientific purposes, the structures established by the law have been formed: the designated veterinarian or expert, the animal welfare committee and the ethics committee (where they are already, they have changed their activity under the new regulations). However, we are concerned about the small number of NTSs published versus the total number of animals used according to statistics and the data of last NTS published (07.03.2017). Also we are fully aware that our conclusion are limited by a relative small number of data, just analysis of NTSs is so far not enough to reflect the stage of implementation of Directive 2010/63/EU in Romania. However, our analyses can provide a general overview about the level of perception and knowledge about laboratory animal science and ethics.

As a conclusion, we can say that the most NTSs reflect a real interest and care for the animal's welfare and legal requirements. We also found NTSs summaries using lacunar and stereotypical 
phrases, which suggest that some applicants see the NTSs just as another bureaucratic task. Additionally, manyNTSs proved alackofknowledge, especially relating to refinement, including the establishing the assessment of severity, pain / stress management, implementing of human end-points. Overall, our recommendation for all scientifically and competent authority personnel is to promote more active the thematic of laboratory animal science into national scientific community, and, on the other hand, to further improving the knowledge and skills of the project responsible, designated veterinarians, establishments responsible, bioethics board members and official veterinarians.

\section{Declaration of interests}

Bogdan Sevastre and Cristin Coman are members of Romanian National Committee for the Protection of Animals used in Scientific or Educational Purposes, but they work as volunteers and do not have financial interests. The others author report no conflicts of interest.

Acknowledgments. This work was supported by a Grant of the Romanian National Authority for Scientific Research and Innovation, CNCS/ CCCDI-UEFISCDI; project number PN-III-P2-2.1BG-2016-0335, within PNCDI III.

\section{References}

1. Directive 2010/63/EU of the European Parliament and of the Council of 22 September 2010, on the protection of animals used for scientific purposes http://www.ansvsa.ro/download/legislatie/bunastare animala/Directiva_Consiliului_2010_63.pdf.
2. Order no. $97 / 2015$ of the President of National Sanitary Veterinary and Food Safety Agency. http://www.ansvsa. ro/download/legislatie/bunastare_animala/Ordin_ ANSVSA_97_2015.pdf

3. Ghid privind modul de autorizare sanitara veterinara a proiectelor care implica utilizarea animalelor in proceduri; http://www.ansvsa.ro/download/ghiduri_-_toate/ ghid_animale_scop_stiintific/Ghid-privind-modul-deautorizare-sanitara-veterinara-a-proiectelor-careimplica-utilizarea-animalelor-in-proceduri.pdf

4. National Competent Authorities for the implementation of Directive 2010/63/EU on the protection of animals used for scientific purposes. Working document on Project Evaluation and Retrospective Assessment; http:// ec.europa.eu/environment/chemicals/lab_animals/pdf/ guidance/project_evaluation/en.pdf

5. National Competent Authorities for the implementation of Directive 2010/63/EU on the protection of animals used for scientific purposes. Working document on severity assessment framework. http://ec.europa.eu/ environment/chemicals/lab_animals/pdf/guidance/ severity/en.pdf

6. Rezumate cu caracter non tehnic; http://www.ansvsa.ro/sanatate-bunastare-si-nutritieanimala/bunastarea-animalelor/

7. Coman C, Gonciarov M, Marinescu B (2017). Ethical evaluation and authorization of projects to use animals in experimental procedures. Bucharest:Printech, (chapter 7)

8. Smith D, Anderson D, Degryse AD, Bol C, Criado A, Ferrara A, Franco NH, Gyertyan I, Orellana JM, Ostergaard G, Varga O, Voipio HM (2018). Classification and reporting of severity experienced by animals used in scientific procedures: FELASA/ECLAM/ESLAV Working Group report. Lab Anim.; 52(1_suppl):5-57.

9. Law no. 43 of 11 April 2014 of the Romanian Parliament on the protection of animals used for scientific purposes. http://www.ansvsa.ro/download/legislatie/bunastare animala/Legea_43_2014.pdf 